\title{
ANÁliSE DO AUTOCONTROLE EM ALUNOS ALFABETIZADOS SOB A PERSPECTIVA DA INTELIGÊNCIA EMOCIONAL
}

\author{
Maria Veronica Santana Sales ${ }^{1}$ \\ Maria Aparecida Santos e Campos ${ }^{2}$
}

RESUMO: A inteligência emocional é versada como a competência que proporciona ao indivíduo a habilidade de reconhecer, gerir e regular suas próprias emoções. Esta investigação retrata o nível das habilidades da inteligência emocional, especificamente, o autocontrole de discentes de duas instituições sendo que uma tem em sua grade curricular programas de desenvolvimento da inteligência emocional e a outra não dispõe desse benefício. O objetivo é analisar o efeito da aprendizagem emocional em alunos alfabetizados sob a perspectiva da inteligência emocional do Colégio Atena e comparar aos da Escola Tancredo Neves, não alfabetizados emocionalmente. O método se deu por um estudo de caráter descritivo, situada na visão Psicolinguística e Cognitiva, Educação e inteligência emocional: cultura e desenvolvimento pessoal, apoiada teoricamente nos estudos das emoções, inteligência emocional, gerenciamento e regulação das emoções, com abordagem quali-quantitativa e correlacional, cuja amostra contou com ro4 estudantes. Para recolha de dados foi utilizado o questionário (Medida de Inteligência Emocional - MIE). Nos resultados, observou-se que os inquiridos da Escola Tancredo Neves apresentam ligeiro resultado positivo comparado ao Colégio Atena. Todavia, percebe-se, no panorama geral, quanto ao domínio das emoções, que não se pode considerar satisfatório os resultados em ambas as instituições visto que em vários aspectos menos de $50 \%$ dos questionados apontam pouca capacidade para lidar bem com as emoções. Conclui-se que as emoções tendem a se manifestarem na forma de padrões de pensamentos, sentimentos, comportamentos e influências, contudo, são moldáveis, ou seja, podem ser aprendidas em contextos formais e informais de aprendizagem, portanto não se pode ignorar a interferência provocada no comportamento dos humanos, o que exige uma maior conscientização e envolvência por

\footnotetext{
Doutoranda em Educação pela Universidad Internacional Iberoamericana (UNINI- MX). Mestra em Ciências da Educação pela Universidade Lusófona de Humanidades e Tecnologias, ULHT, Portugal, (2015). Especializada em Educação, desenvolvimento e políticas educativas. CINTEP/PB, CCITP_PPROV, Brasil. Especializada em psicopedagogia institucional. Faculdade Atlântico (FA), Brasil. Graduada em Letras Português/Inglês - Universidade Federal de Sergipe, UFS, Brasil. Correio eletronico: projetecmv@gmail.com. Orcid oooo-0003-1340-47IX

${ }^{2}$ Doctor en Actividad Física y Salud por la Universidad de Jaén (2013), Máster en Estudios Avanzados - DEA por la Universidad de Jaén (2009), Graduado en Licenciatura en Educación Física por el Instituto Católico de Minas Gerais (1992). Catedrático de Actividades Terapéuticas de la Asociación Jienense de Fibromialgia e Investigador Colaborador de la Universidad de Jaén. Correo electrónico: maria.santos@unini.edu.mx. Orcid oooo-ooor-7190-5438.
} 
parte dos gestores da educação no sentido de aplicabilidade no currículo escolar relativos às componentes emocionais.

Palavras-chave: Inteligência emocional. Emoções. Autocontrole.

ABSTRACT: Emotional intelligence is versed as the competence that provides individuals with the ability to recognize, manage, and regulate their own emotions. This research portrays the level of emotional intelligence skills, specifically, the self-control of students from two institutions, one of which has emotional intelligence development programs in its curriculum, while the other does not have this benefit. The objective is to analyze the effect of emotional learning on students who are emotionally literate from the perspective of emotional intelligence at Atena College and compare it with those from Tancredo Neves School, who are not emotionally literate. The method was a descriptive study, situated in the Psycholinguistic and Cognitive view, Education and emotional intelligence: culture and personal development, theoretically supported in the studies of emotions, emotional intelligence, management and regulation of emotions, with a quali-quantitative and correlational approach, whose sample included I04 students. For data collection, the questionnaire (Emotional Intelligence Measure - EIM) was used. In the results, it was observed that the respondents from Tancredo Neves School show a slight positive result compared to Atena College. However, it can be noticed, in the general context, regarding the domain of emotions, that the results in both institutions cannot be considered satisfactory, since in several aspects less than $50 \%$ of the respondents indicate a low capacity to deal well with emotions. It is concluded that emotions tend to manifest themselves in the form of patterns of thoughts, feelings, behaviors and influences, however, they are moldable, that is, they can be learned in formal and informal learning contexts, therefore, one cannot ignore the interference caused in the behavior of humans, which requires a greater awareness and involvement on the part of education managers in the sense of applicability in the school curriculum related to emotional components.

Keywords: Emotional intelligence. Emotions. Self-control.

\section{INTRODUÇÃO}

A escola possui autonomia para atuar diretamente na formação emocional e acadêmica dos indivíduos, e, nesse processo educativo, todas as ações celebradas no ambiente escolar influenciam o comportamento dos discentes, podendo intuir e transformá-los. O caráter regulatório quase sempre se encontra implícito na cultura escolar e são emitidos, geralmente, em ações planejadas, intencionais, todavia, práticas relacionadas ao desenvolvimento da inteligência emocional (IE) não são refletidas ou questionadas; não são levadas em conta na formação do indivíduo. 
Apesar de deparar-se com uma diversidade dos perfis com dificuldades de aprendizagem e descontrole emocional, não se evidencia programas que visem o desenvolvimento da inteligência emocional nas escolas, notadamente, nas instituições públicas. Nota-se que algumas escolas privadas, já tomaram consciência da necessidade de incluir no currículo programas que proporcione a formação e desenvolvimento emocional dos estudantes, pois compreendem que a aprendizagem não está isolada, mas conectada numa rede de interdependências e permeada pelo jogo do poder da emoção no desenvolvimento acadêmico, além de ser constituinte das relações sociais.

Sabe-se que o desenvolvimento da aprendizagem está atrelado aos processos cognitivos e emocionais. Assim, a aprendizagem emocional vai além da dimensão cognitiva e importa aos indivíduos reconhecer e regular as próprias emoções, tomar decisões equilibradas, responsáveis e conscientes, nesse sentido, Machado (2020) ressalta que:

\footnotetext{
As emoções, como parte dos ecos que ressoam no que por processos seculares vêm se tentando fixar como forma de identidade individualizante, se configuram e se expressam por uma constante dinâmica entre os fatores biológicos, fisiológicos e mímicas, gestos, atitudes, cadências próprias de um espaço que, ao se entenderem universais nos impede de perceber essa imensa multiplicidade muitas vezes intraduzível entre territórios distantes.
}

As questões emocionais foram paulatinamente ganhando lugar ao reconhecimento e importância ao ponto que grandes estudiosos fazem alusão ao Quociente de Inteligência (QI) afirmando que a "inteligência emocional não são capacidades que se opõem, mas distintas". Para o autor há uma tendência de mesclar a "acuidade intelectual e emocional; as pessoas de alto QI e baixa inteligência emocional (ou baixo QI e alta inteligência emocional) são, apesar dos estereótipos, relativamente raras” (GOLEMAN 2012, p. 68).

O desenvolvimento das emoções deve, portanto, fazer parte do currículo escolar desde a pequena infância. Entende-se que nas fases iniciais da escolaridade, o desenvolvimento emocional desempenha um papel essencial para a vida e constitui a base ou condição necessária para o progresso da criança nas diferentes dimensões do seu desenvolvimento.

Diante dessa veemência, este estudo objetivou analisar o efeito da aprendizagem emocional em alunos alfabetizados sob a perspectiva da inteligência emocional dos $8^{\mathfrak{o}}$ e $9^{\underline{o}}$ ano do Colégio Atena e da Escola Tancredo Neves, sendo a primeira, instituição particular, 
contemplada pelo programa de desenvolvimento da inteligência emocional e a outra, escola pública, e não faz parte de programas que contemple o crescimento emocional. Ademais, complementa-se a pesquisa com o estudo comparativo do resultado dos dois grupos.

Dada a amplitude das dimensões associadas aos conceitos de inteligência e competências emocionais, o autocontrole é parte integrante nessa investigação, e, sobre esse domínio incide a pesquisa que aborda diretamente a questão do comportamento dos discentes das escolas citadas.

\section{REFERENCIAL TEÓRICO}

Mayer, Salovey e Caruso (200o, p. 267), destacam que a Inteligência Emocional (EI) estaria relacionada com "a capacidade de perceber emoções, assimilá-las com base nos sentimentos, avaliá-las e geri-las”. Sob a perspectiva de Siqueira e Santillo (2019, p. I2) afirmam que a inteligência emocional consiste na "capacidade do ser humano de identificar emoções e sentimentos em si mesmo e nos outros e, quando se trata de si mesmo, ser capaz de controlá-las e conseguir manter um equilíbrio emocional e coerente com a realidade".

Para Le Berton (2019, p.146) "as emoções traduzem a ressonância afetiva do acontecimento de maneira compreensível aos olhos dos outros", sem origem individualizada, é uma inferência resultante de um aprendizado pessoal e de identificação. Para o autor, "a emoção é a definição sensível do acontecimento tal como o vive o indivíduo, a tradução existencial imediata e íntima de um valor confrontado com o mundo".

Nesse sentido, para ser inteligente emocionalmente o indivíduo deve ter a capacidade de reconhecer suas emoções e compreender como influenciam em seus pensamentos e comportamento. No mesmo viés, envolve a capacidade de controlar os sentimentos e impulsos e entender as emoções alheias, ser sociável e motivado. Nesse sentido, Goleman (2012, p. 8o) sustenta que "A capacidade de manter o autocontrole, de suportar o turbilhão emocional que o acaso nos impõe e de não se tornar um "escravo da paixão" tem sido considerado desde Platão, como uma virtude".

Entretanto, os episódios diários podem desencadear emoções positivas ou negativas, que estão associadas a eventos significativos das reações do indivíduo a determinadas situações. Estas reações podem ser apropriadas ou inadequadas, dependendo da forma como 
se lida com o problema. Diante dessa realidade entende-se que emoções se dão, segundo Souza, Hickmann, Asinelli-Luz, \& Hickmann, (2020, p. 39I) basicamente através dos "mecanismos biológicos ligados ao modo como os seres humanos agem ou reagem diante de determinados fatos ou acontecimentos. Elas estão diretamente ligadas ao valor que as pessoas atribuem às coisas e/ou às circunstâncias”. Para os autores, as especificidades das emoções podem influir nos " os aspectos de punição e de recompensa contribuem para revelar impulsos e motivações relacionados às necessidades humanas”.

Entende-se que a inteligência emocional está inserida na primazia de encarar situações incertas, a exemplo de conflitos, frustrações, perdas e até mesmo sucesso, assimilando, regulando e gerenciando as emoções ao próprio favor na tomada de decisões racional e adequada. Nessa proposta, amplia-se a representatividade da inteligência emocional a capacidade de enfrentar problemas, assumir o controle de situações incertas, "não deixando que estas comandem nossas ações e pensamentos fazendo com que tomemos decisões inadequadas ou irracionais. A inteligência emocional nada mais é do que a habilidade de conhecer o próximo através dos sentimentos e de se autoconhecer" (MODOLON E VITOR, 2020, p. I4).

Leite, discorre sobre os benefícios do desenvolvimento da IE e apresenta aspectos importantes ao afirmar que "A inteligência emocional é a característica primordial em uma pessoa. Possuí-la significa favorecer as relações com os outros e consigo mesma, possibilitando a aprendizagem, a resolução de conflitos e o bem-estar pessoal e social" (LEITE, 2019, p.6o8).

Sabe-se que a inteligência emocional é expansiva e há cinco domínios referenciados na literatura que consistem em: conhecer-se; controlar-se; motivar-se; reconhece as emoções nos outros; lidar com relacionamentos, assim, Amestoy (2020, p. 4) define os domínios da IE como

A compreensão da inteligência emocional está relacionada ao conhecimento dos pilares que a constituem: autoconsciência, autogestão, automotivação, empatia e gerenciamento de relacionamentos. Tal habilidade está associada às relações intrapessoais, correspondentes à pessoa e interpessoais, que são estabelecidas com o grupo. 
Nesse sentido, mesmo que pareça as emoções serem parte do nosso património genético, é desenvolvível e moldável, portanto é uma questão de escolha, pode-se administrá-las e revezá-las.

Diante do construto de Salovey e Mayer, Goleman (2012) apresenta cinco habilidades ou competências da inteligência emocional divididas nas dimensões intrapessoal, a saber: autoconsciência, autocontrole e automotivação; e interpessoal: empatia e sociabilidade. Assim, "Buscar o autoconhecimento dessas realidades, é tornar consciente o ser emocional que existe em cada indivíduo, utilizando-se da consciência como ferramenta primordial de transformação. (COSTA, 2017, p. 22).

A autoconsciência abarca a capacidade de a pessoa ter consciência da sua própria consciência e assim ser capaz de se reconhecer-se, fazer a leitura de suas emoções no exato momento que elas ocorrem ou depois através da autorreflexão, portanto, considera Goleman (2012, p.70) que "Nessa consciência autorreflexiva, a mente observa e investiga o que está sendo vivenciado, incluindo as emoções”. Assim, Amistoy, (2020, p. 5) elenca a autoconsciência como o alicerce da inteligência emocional e, segundo dito autor, a autoconsciência é o meio que o indivíduo trilha para exercer a capacidade de afastar a negatividade e mergulhar na autorreflexão diante dos desafios.

Nesse contexto, Hansen, Fabricio, Rotili, \& Lopes, (2018, p.6) fomentam que a autoconsciência "é o primeiro componente da inteligência emocional. A autoconsciência significa uma compreensão profunda das próprias emoções, forças, fraquezas, necessidades e impulsos". E ainda, segundo os autores, os indivíduos autoconscientes são ponderados em suas críticas e não são irrealisticamente esperançosas. No que se refere a automotivação, trata-se da capacidade de motivar a si mesmo direcionando as emoções em função de um determinado objetivo, assim, os indivíduos automotivados tendem a ser mais eficientes e produtivas. Para Amistoy (2020, p.5) a automotivação se ocupa em "utilizar a energia gerada pelas emoções para o alcance de objetivos e metas pessoais, bem como auxiliar para que a pessoa se torne mais eficiente com os percalços vivenciados no decurso da vida".

Sintetiza-se que a automotivação se sobrepõe a recompensa ou retorno do mero objetivo monetário ou de status. 
A empatia envolve a interação com o outro no que envolve compreensão e solidariedade. "A empatia é alimentada pelo autoconhecimento; quanto mais consciente estivermos acerca de nossas próprias emoções, mais facilmente poderemos entender o sentimento alheio". (GOLEMAN, 2012, p. II8). O dito autor reconhece que a empatia é uma importante componente de liderança.

O exercício da empatia consiste no se pôr no lugar do outro, sentir em conjunto com o outro e agir em prol do outro. Nesse viés, Godiel Ramos (2018) menciona que a interação entre as pessoas se dá por meio da empatia, ademais, desenvolve a capacidade de escuta, a reação emocional para com o outro; e a reação cognitiva, que consiste na capacidade de perceber o ponto de vista alheio, como componentes da empatia.

Nota-se que a empatia está relacionada com a capacidade que o indivíduo tem de através do autoreconhecimento e interação consigo mesmo seja capaz de reconhecer o outro. Nesse aspecto, Amistoy (2020, p. 5) afirma que "quanto mais consciente as pessoas estiverem das próprias emoções, mais facilmente poderão entender os sentimentos alheios, ou seja, é a capacidade de saber como o outro se sente".

A sociabilidade corresponde a capacidade de o indivíduo gerir as relações interpessoais na construção da convivência e de redes de contatos. Como salienta Goleman (1995, p. 56), "estas são as aptidões que reforçam a popularidade, a liderança e a eficiência interpessoal".

Por esse viés, Leite (2019, p. 607) assevera que "O indivíduo, a partir de sua convivência social de seu entorno, carrega uma carga de herança cultural que se constrói ao longo de sua histórica trajetória de desenvolvimento enquanto aprendente pela arte de conviver com os seus pares".

O autocontrole é outra capacidade defendida por Goleman (2015, p. 16) "o autocontrole é uma conversa interior contínua, é o componente da inteligência emocional que nos liberta de sermos prisioneiros de nossos sentimentos". O autocontrole ou gestão das emoções se refere a capacidade do sujeito em controlar as suas emoções e inerentes manifestações, consiste em pensar antes de agir consiste na autogestão, autorregulação. Desse modo, no que se refere ao autocontrole, de Oliveira, de Figueiredo, \& Dutra (2020, p. 19I) ponderam que 
Ainda, existe uma urgência de que os indivíduos a cada dia alcancem aprendizados que intentem o controle das emoções, a resolução pacífica, tranquila, equilibrada e com discernimento de conflitos para uma boa convivência no meio ambiente de trabalho e no ambiente social.

Conclui-se que a maestria de exercer o autocontrole denota ao indivíduo inteligência emocional no que se refere a capacidade de contornar problemas, resolver conflitos e manter o equilíbrio.

\section{O GERENCIAMENTO DAS EMOÇÕES}

Entende-se que para ser emocionalmente inteligente se faz necessário exercitar e desenvolver a inteligência emocional. Sabe-se que o controle emocional não é algo nato, é, portanto, moldável e exercitável.

Segundo Sales e Campos (2021, p. 51) "o gerenciamento das emoções é algo pessoal, intransferível, responsabilidade de cada indivíduo, impossível atribuir a outrem” assim, entende-se que a maioria das competências desenvolvida para uma vida plena são de origem emocional. Aprender a regular as próprias emoções e as emoções dos que nos rodeiam faz parte de um processo educativo, de caráter não intelectual. O que os indivíduos sentem sobre as suas experiências de aprendizagem são tão importantes como o que aprendem. $O$ gerenciamento das emoções, que consiste na consequente execução da autoavaliação, perpassando pelo gerenciamento dos pensamentos é o passo principal para atingir o autocontrole.

De Morais, Sauerbronn, Oliveira \& Pestana, (2015) elaboraram técnicas de gerenciamento das emoções que consistem na ação do corpo comandado pela alteração psicológica o sujeito controla suas funções físicas; mudança externa se dá pela manipulação de expressões faciais; mudança interna consiste no estimulo de sentimentos; e, o trabalho cognitivo consiste em desenvolver o pensamento consciente no esforço de gerar sentimentos apropriados.

Nesse sentido, gerenciar as emoções requer técnicas que segundo Cury (2017, p. 28) é preciso treinar e "reeditar janelas traumáticas ou reconstruir janelas saudáveis". Percebe-se, contudo, que o indivíduo precisa aprender a ser autor da própria história. 


\section{REGULAÇÃO DAS EMOÇÕES}

A regulação emocional é entendida como o processo de conduzir os estados emocionais internos buscando moldar a intensidade e duração. Na visão de Ricarte (2016, p. ıo) "O termo regulação emocional, refere-se à capacidade de tolerar reações emocionais agradáveis ou desagradáveis, compreendendo-as sem exageros ou diminuição de sua importância, assim como, controlá-las ou descarregá-las apropriadamente”.

A regulação das emoções exige do indivíduo maturidade emocional, além da anatomia cerebral, precisamente as áreas responsáveis pelas emoções, em perfeito estado. Segundo Siqueira (2018, p. 39):

Pacientes com lesões de córtex pré-frontal ventromedial exibem, geralmente, uma resposta emocional reduzida, bem como redução acentuada das emoções sociais (por exemplo, compaixão, vergonha e culpa) que estão intimamente associadas a valores morais e também exibem baixa tolerância à raiva e à frustração em certas circunstâncias.

O que representa dizer que a regulação da emoção não é inerente a pessoas com distúrbios ou lesões no córtex pré-frontal ventromedial. Xavier (2019, p. 35) sustenta que "O que caracteriza essencialmente regulação emocional são conjuntos de estratégias com objetivo de influenciar a trajetória da emoção", isto é, manejar as emoções e descartar as inadequadas.

Nesse viés, observa-se que o desenlaçar das emoções está nos entrelaços das mais variadas vivências experienciadas no dia a dia. Se a manifestação das emoções não está bem correspondida nas mais diversas situações é praticável a regulação, dessa forma, melhora-se a conciliação das demandas internas com a realidade externa, nesse pensamento, (Gross, 2008) formulou uma base conceitual para o campo da regulação emocional e apresentou cinco processos, em seu modelo de estratégias, que regula as emoções, a saber: seleção da situação, modificação da situação, redirecionamento da atenção, mudança cognitiva e modulação da resposta.

Discorrendo sobre a elaboração apresentada por Gross e interpretada por Xavier (2019, p.35) se pode afirmar que esses processos se compõe conforme é selecionada a situação com a possibilidade de manipular e transformar a emoção, uma vez modificada se possibilita a alteração das características externas na tentativa de influenciar as emoções que contribui 
para o redirecionamento da atenção alterando assim, a resposta "e na modulação da resposta o indivíduo interpõe esforços para influenciar suas respostas comportamentais ou fisiológicas, por vezes ambas, que são geradoras de impactos emocionais”

Contudo, levanta-se a suposição de que é possível moldar as emoções daqueles que, em virtude de suas experiências, não adquiriram competências emocionais suficientes. Por meio de treinamento pode-se desenvolver habilidades para melhor reconhecer seus sentimentos, expressá-los e regulá-los, pois conforme Leite (2019, p. 607) "As pessoas, ao se situarem no mundo, são intrincadas de competências que necessitam ser lapidadas durante o período de escolarização. A inteligência emocional é um dos elementos importantes de um ser humano". Por outro lado, esse treinamento pode se estender às escolas, criando e oferecendo meios de desenvolvimento da inteligência emocional para que nelas se processem os domínios das aptidões emocionais,

\section{PROCEDIMENTO METODOLÓGICO}

A amostra foi constituída por I04 discentes do Ensino Fundamental de duas instituições de ensino, sendo 57 do Colégio Atena e 47 da Escola Tancredo Neves, Sergipe. A Tabela I apresenta as características sócio-demográficas da amostra em cada uma das escolas.

A realização da investigação se deu pelo questionário MIE (Medida de Inteligência Emocional). $\mathrm{O}$ instrumento MIE foi priorizado por se tratar de uma medida validada para uso em pesquisas humanas, contempla os interesses levantados pela problemática e se adequa a população pesquisada.

O questionário Medida de Inteligência Emocional - MIE, Siqueira, Barbosa e Alves (1999) consiste em 59 itens escalares com quatro pontos cada um (I- nunca; 2- poucas vezes; 3- muitas vezes; 4- sempre), avaliando cinco dimensões fatoriais, contudo, neste estudo, apenas se utilizou os ıo itens que medem o autocontrole, isto é, investiga a facilidade ou dificuldade de administrar os próprios sentimentos, gerenciar e regular as emoções, pensamentos e comportamentos.

Quanto à abordagem, trata-se de uma pesquisa quali-quantitativa que de acordo com Richardson (1999) e Fonseca (2002) é caracterizada pelo uso da quantificação, tanto na coleta 
das informações quanto no tratamento delas por meios estatísticos, é enfatizada na objetividade e para expor as causas dos acontecimentos utiliza de linguagem matemática.

A técnica de coleta de dados se deu através de questionário, sendo um procedimento de investigação, que coleta informações da realidade, com o objetivo de conhecer as opiniões, os sentimentos e situações vivenciadas pelas pessoas (GIL, 2008).

Foram aplicados questionários compostos por io questões sendo 5 de conotação positiva e 5 de conotação negativa nas escalas sempre, muitas vezes, poucas vezes e nunca), para um universo de ro4 alunos do Ensino Fundamental da Escola Tancredo Neves e do Colégio Atena. Os dados foram tabulados e submetidos a uma análise estatística simples.

No momento da coleta dos dados a pesquisadora, deslocou-se até as escolas, conforme previamente acordado, no momento da aula, na presença do docente regente, foi entregue a cada discente um questionário, o TCLE, em envelope, acompanhado de uma caneta e um par de luvas.

A fim de tornar a pesquisa discreta e confidencial, optou-se por acontecer em horário de aula, na escola que estudam, fazendo-se o preenchimento do questionário indiviso. Os discentes foram aconselhados a ler pausadamente cada questão e esclarecidos que teriam tempo livre para responder, isto é, seria respeitado o ritmo de cada um. Enfatizou-se a ausência de respostas corretas ou incorretas, garantiu o anonimato dos respondentes e permaneceu disponível para os eventuais esclarecimentos das questões, reforçando a importância de se responder todos os itens.

Os dados foram tabulados e submetidos a uma análise estatística simples. A análise dos dados foi feita por meio de análise de conteúdo associado a um rasgo quantitativo associado ao quantitativo. Se utilizou o programa de Exel e SSPS, para organização e tabulação dos dados.

A análise de conteúdo foi realizada nos questionários. Os conteúdos foram analisados de acordo com reflexões produzidas sobre as questões objetivas, as quais contêm aspectos quantitativos em relação às questões emocionais dos investigados.

No que se refere à natureza dos objetivos metodológicos a presente pesquisa é considerada descritiva, uma vez que busca descrever as características de determinada população ou determinado acontecimento, sendo ele utilizado no presente estudo (GIL, 
2008). Ademais, para tanto, leva-se em conta o que diz Santos (2012, p.4) "Na fase de interpretação dos dados, o pesquisador precisa retornar ao referencial teórico, procurando embasar as análises dando sentido à interpretação".

Assim, a análise dos aspectos quali-quantitativos da pesquisa bem como os resultados serão apresentados em dados estatísticos descritivos.

\section{RESULTADOS E DISCURSÃO}

Com respeito aos dados sociodemográficos, a questão referente aos dados sobre o gênero dos participantes pode ser constatada na tabela I

Tabela r: Dados sociodemográficos dos alunos das duas escolas participantes (sexo).

\begin{tabular}{|c|c|c|c|c|c|}
\hline $\begin{array}{c}\text { Participantes do Colégio } \\
\text { Atena }\end{array}$ & No & $\%$ & $\begin{array}{c}\text { Participantes da Escola } \\
\text { Tancredo Neves }\end{array}$ & No & $\%$ \\
\hline Masculino & 25 & 43,9 & Masculino & 24 & 5 I,I \\
\hline Feminino & 32 & $56, \mathrm{I}$ & Feminino & 23 & 48,9 \\
\hline \multicolumn{6}{|c}{ Total de participantes no estudo I04 } \\
\hline \multicolumn{6}{|r}{} \\
\hline
\end{tabular}

No que tange ao fator gênero (masculino, feminino), verificou-se maior presença do sexo feminino no Colégio Atena, ainda que os valores demonstram que esta prevalência é pequena, apresenta uma quase paridade entre os sexos. Este resultado demonstra significativo equilíbrio quanto ao gênero, o que denota austeridade quanto a essa variável.

Tabela 2: Dados sociodemográficos dos alunos das duas escolas participantes (idade).

\begin{tabular}{|c|c|c|c|c|c|c|}
\hline $\begin{array}{c}\text { Distribuição da amostra } \\
\text { idade }\end{array}$ & I2 anos & I3 anos & I4 anos & $\begin{array}{c}\text { I5 } \\
\text { anos }\end{array}$ & $\begin{array}{c}\text { I6 } \\
\text { anos }\end{array}$ & $\begin{array}{c}\text { I7 } \\
\text { anos }\end{array}$ \\
\hline Escola Tancredo Neves & o & 2 & 29 & 3 & I2 & I \\
\hline Colégio Atena & 24 & 7 & 24 & o & o & 2 \\
\hline
\end{tabular}

A análise das figuras 2, relativos à distribuição da amostra por idade, o maior número de respondentes situa-se no intervalo correspondente à faixa etária entre os (I2 e I4) anos em 
ambas as escolas. Além disso, cabe ressaltar que a faixa etária de (17) anos, é a menor, constituindo apenas $2,9 \%$ da amostra total.

Observa-se uma paridade entre as idades dos alunos das duas escolas, que mostra a maioria dos alunos estão dentro da faixa etária esperada para estas séries, porém se comprova um desvio do padrão notável na Escola Tancredo Neves representado pelos alunos de idade entre 16 e 17 anos.

Uma vez efetuada a caracterização dos dados gerais (idade, gênero), relativos à amostra, passa-se à abordagem dos resultados seguintes do questionário.

Como já frisado, neste estudo, importa analisar o autocontrole, sendo a capacidade mencionada por Goleman (2015), que consiste na autogestão e se trata de um diálogo íntimo e constante que dá a liberdade ao indivíduo de não se aprisionar aos sentimentos.

Ao tratar da referida competência, segundo Tamayo (2006) há três condutas que o indivíduo pode utilizar das quais espelha o autocontrole ou a ausência dele; a passiva, que representa o comportamento inibido, introvertido, frustrado e ansioso; a agressiva, comportamento que o sujeito humilha, é explosivo, hostiliza o outro, é autoritário; e a assertiva, que segundo o dito autor é a viável, nesta, o indivíduo tem escolha própria, entende, reconhece e defende seus direitos, respeita as emoções do outro.

Primariamente, analisa-se os itens de conotação positiva. Neles, as afirmativas (sempre) equivale a um grau de autocontrole elevado, (muitas vezes), moderado; (poucas vezes), fraco; e (nunca) representa nenhum equilíbrio emocional.

Tabela 3: Resultado da dimensão autocontrole no que se refere a ponderar as respostas.

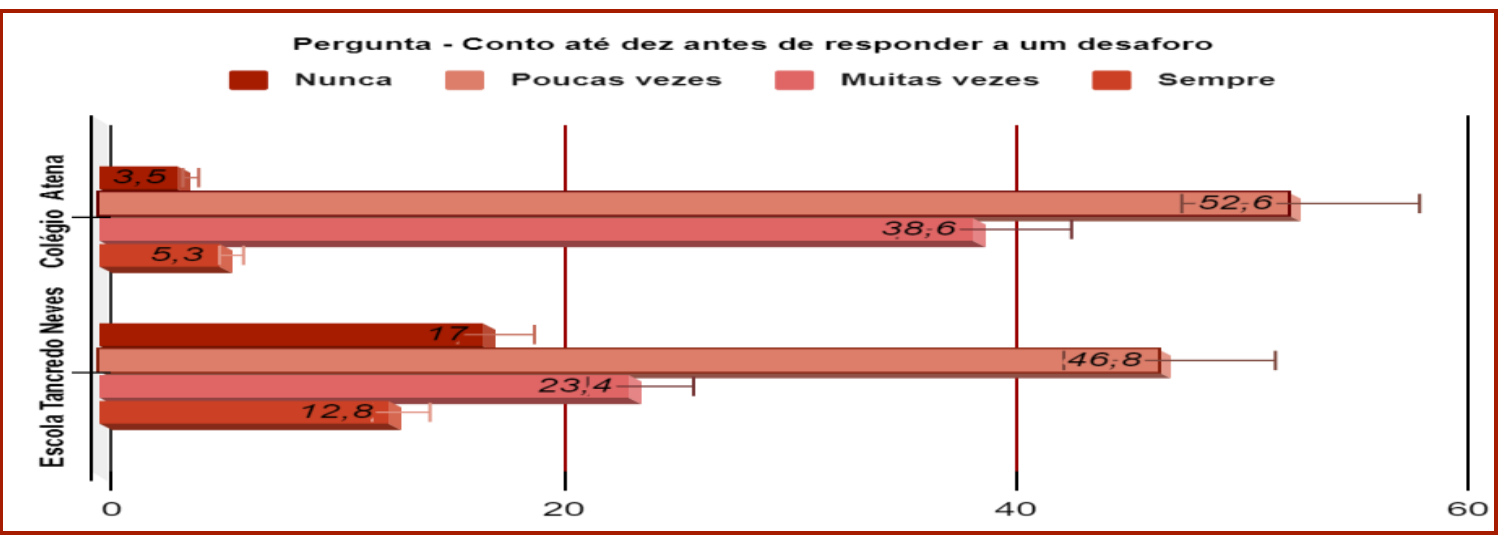


Nesse item, nota-se que dos 57 pesquisados do Colégio Atena (30) nunca tem controle sobre os desaforos recebidos, (22) poucas vezes, apenas (3) muitas vezes e (2) sempre. Dos 47 estudantes inquiridos na Escola Tancredo Neves (22) nunca pensam antes de responder a um desaforo, (II) poucas vezes, (6) muitas vezes e (8) sempre. Aqui se evidencia fraco domínio do autocontrole emocional na população pesquisada, em ambas as escolas, todavia, observa-se ligeira pior capacidade dos discentes da Escola Tancredo Neves.

Nesse contexto, esses indivíduos carecem de aprender a desenvolver as emoções, pois, conforme Cury (2012 p. 4I) "quando formos ofendidos, agredidos, pressionados, coagidos ou rejeitados. Caso contrário, a emoção sempre abortará a razão. A consequência imediata dessa falta de defesa emocional é reagirmos irracional e unifocalmente, e não multifocalmente”.

Tabela 4: Resultado da dimensão autocontrole no que se refere a controle de sentimentos.

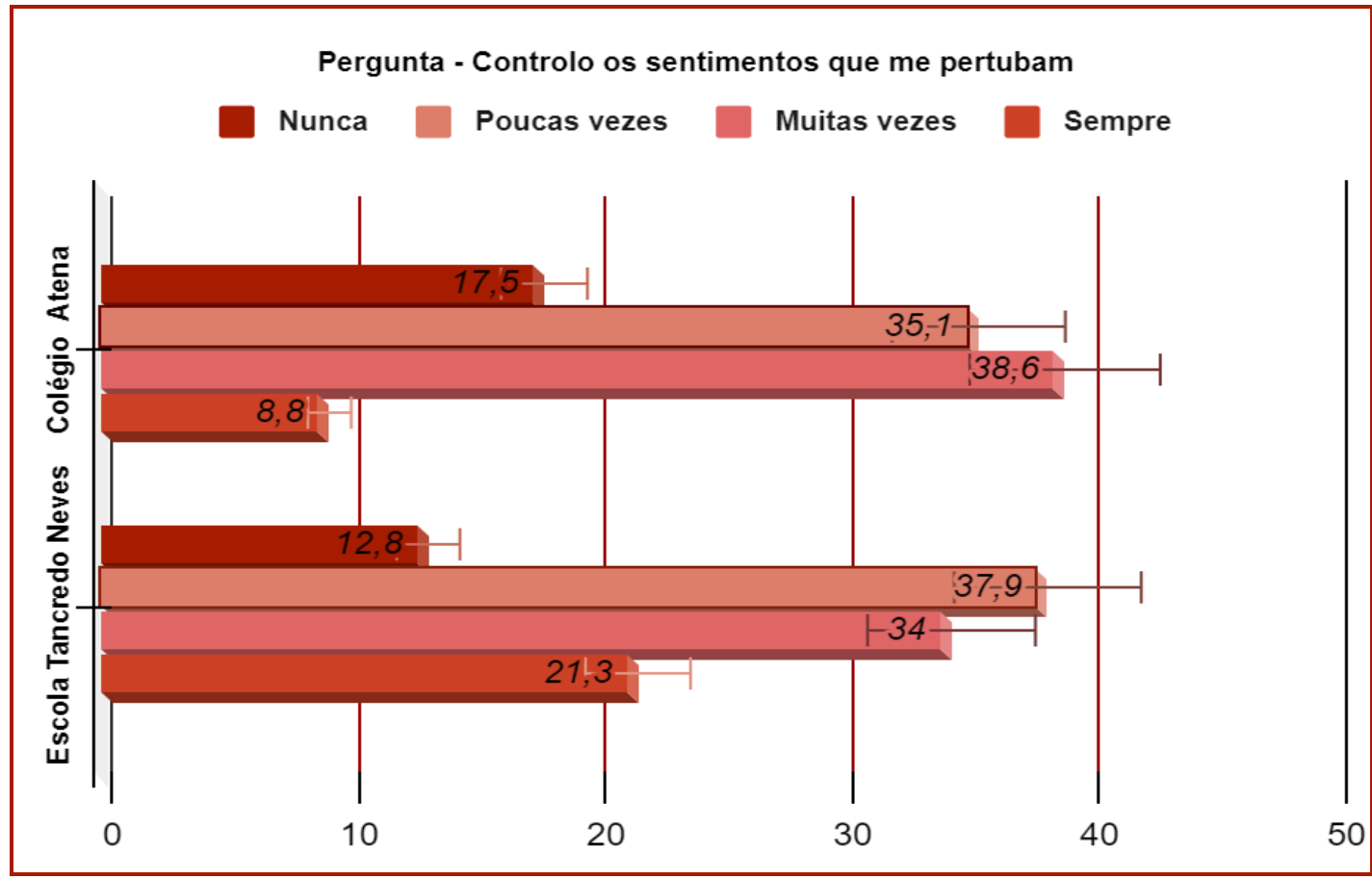

Observa-se neste item, que avalia o enfrentamento intrínseco, (5) dos questionados no Colégio Atena sempre controlam os sentimentos, (22) muitas vezes, (20) poucas vezes e (Io) nunca. Na Escola Tancredo Neves (19) questionados sempre controlam os sentimentos, 
(I6) muitas vezes, (II) poucas vezes e (I) nunca. Agora os pesquisados da Escola Tancredo Neves apresentam melhor domínio emocional nesta questão.

Em vista disso, sobre controlar sentimentos e regular as emoções, segundo Goleman (2015, p. 163) "quando emocionalmente perturbadas, as pessoas não se lembram, não acompanham, não aprendem e nem tomam decisões com clareza”.

Tabela 5: Resultado da dimensão autocontrole no que se refere a reagir com cautela.

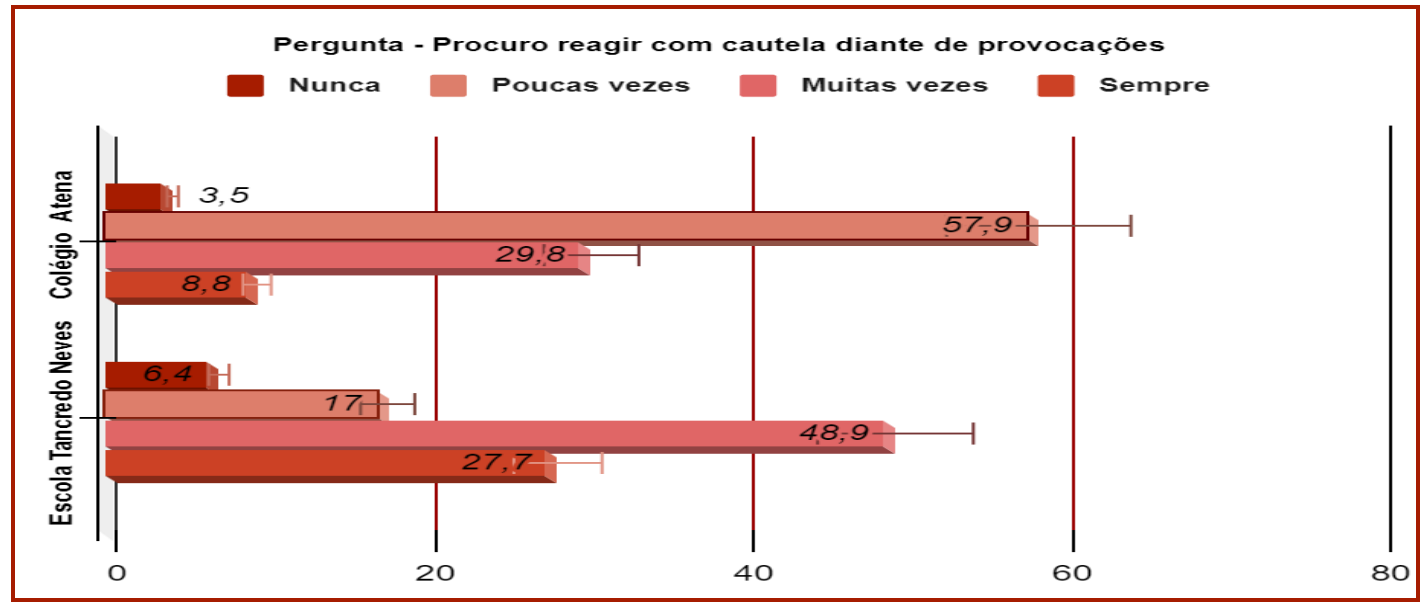

$\mathrm{Na}$ análise do cuidado na forma de reagir a provocações, percebe-se acentuadamente negativo o nível de tolerância no Colégio Atena, sendo que dos 57 somente (5) dos pesquisados sempre reage com cautela, (17) muitas vezes, (33) poucas vezes e (2) nunca. Mirando a Escola Tancredo Neves se percebe um domínio mais acentuado positivamente, visto que dos (47) pesquisados (13) sempre procuram reagir com cautela, (23) muitas vezes, (8) poucas vezes e (3) nunca. Nesta questão a disparidade da reação cautelosa entre as instituições é consideravelmente grande.

Aqui se discute a necessidade da regulação e o gerenciamento das emoções. Entendese que a cautela é uma escolha, e, segundo Berra (2018) a escolha pautada no desenvolvimento da inteligência emocional, torna-se um hábito que se estende a virtude. Nesse sentido, é necessário a autocrítica que, segundo Cury (2015, p.107) “o código da autocrítica é o código de quem se autoavalia, pondera seus atos, julga seus comportamentos, ajusta-se, autocorrigese, reflete sobre suas reações, conjectura consigo mesmo". 
Tabela 6: Resultado da dimensão autocontrole no que se refere a pensar antes de agir.

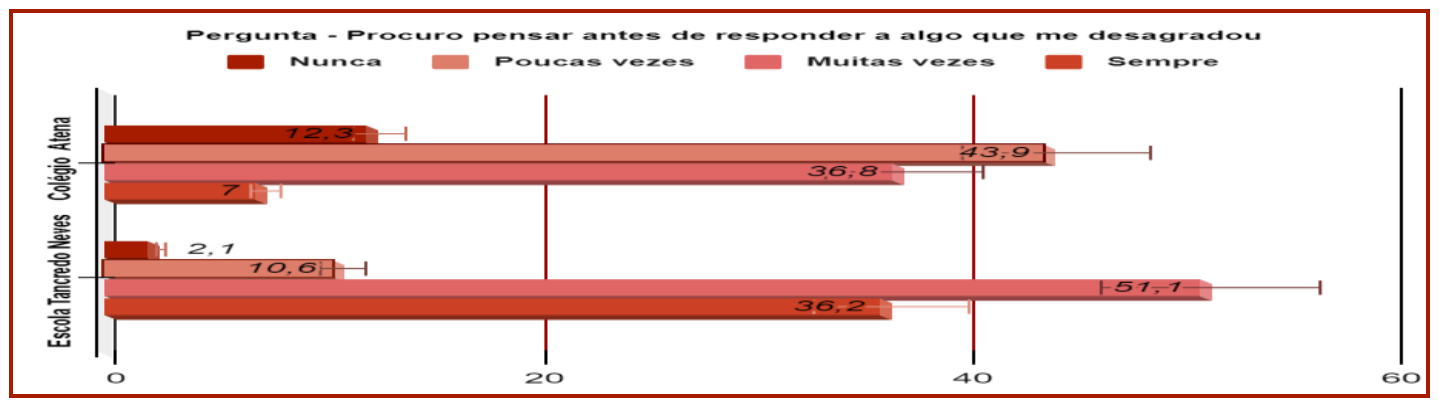

Neste item revela o quanto o indivíduo gerencia os pensamentos, evidencia-se que no Colégio Atena somente (4) afirmam pensar antes de responder a algo que desagradou, (2I) muitas vezes, (25) poucas vezes e (7) nunca. Na Escola Tancredo Neves (17) sempre pensam, (24) muitas vezes, (5) poucas vezes e (I) nunca. Percebe-se que os alunos da Escola Tancredo Neves apresentam, significativamente, melhor capacidade no controle emocional em relação aos alunos do Colégio Atena.

Pelo viés da abordagem do pensar antes de agir, Cury (2019, p. 62) enfatiza que não aprendemos a ser contrariados. "Estamos viciados em reagir quando alguém nos contraria. Quem é impulsivo ou reage sem pensar, além de não proteger a própria emoção, fará de sua memória uma lata de lixo social e destruirá seus melhores relacionamentos”.

A partir daqui, começa-se a análise sobre os itens de conotação negativa, onde (nunca) corresponde a um grau elevado de autocontrole; (poucas vezes), moderado; (muitas vezes) fraco; e (sempre) denota nenhum autocontrole emocional.

Tabela 7: Resultado da dimensão autocontrole no que se refere a falar sem pensar.

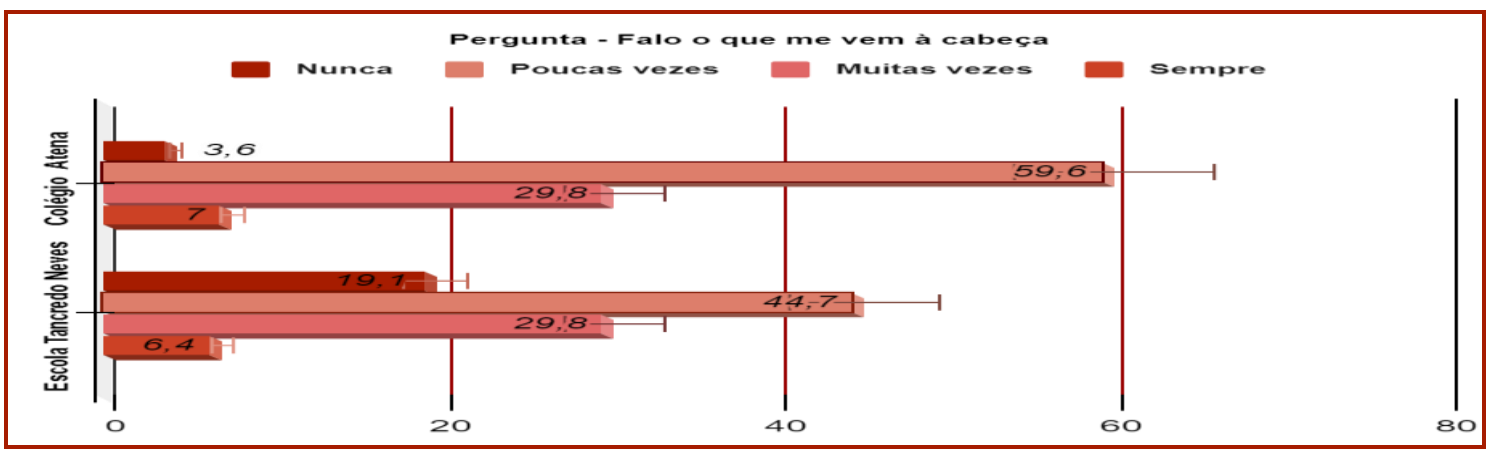

O gráfico acima demonstra o autocontrole no que se refere ao falar sem pensar e, observa-se considerável controle nas duas instituições, sendo que (4) dos inquiridos no 
Colégio Atena sempre falam o que vem à cabeça e (17) muitas vezes, (34), por sua vez, poucas vezes e (2) nunca. Desse modo, dos discentes da Escola Tancredo Neves (3) assumiram sempre, (14) muitas vezes, (2I) poucas vezes e (9) nunca. Denota-se que os questionados da Escola Tancredo Neves se apresentam ligeiramente melhor controlados comparados aos discentes do Colégio Atena.

$\mathrm{Na}$ ausência de gerenciamento dos pensamentos, para Cury (2015, p. II5) “Quem se orgulha de dizer tudo que pensa machuca quem mais deveria ser amado. Não decifrou a linguagem do autocontrole". Infere-se que o controle das emoções não vem de herança genética nem tão pouco é comerciável, sua aquisição se dá através do treino e desenvolvimento do domínio, da gestão e regulação. Nesse sentido, Modolon e Vitor, (2020) enfatizam que a inteligência emocional pode ser trabalhada e desenvolvida, e é por meio de escolher aprender a gerir as emoções que se dá o melhoramento e aperfeiçoamento do autocontrole.

Tabela 8: Resultado da dimensão autocontrole no que se refere a reagir a insulto.

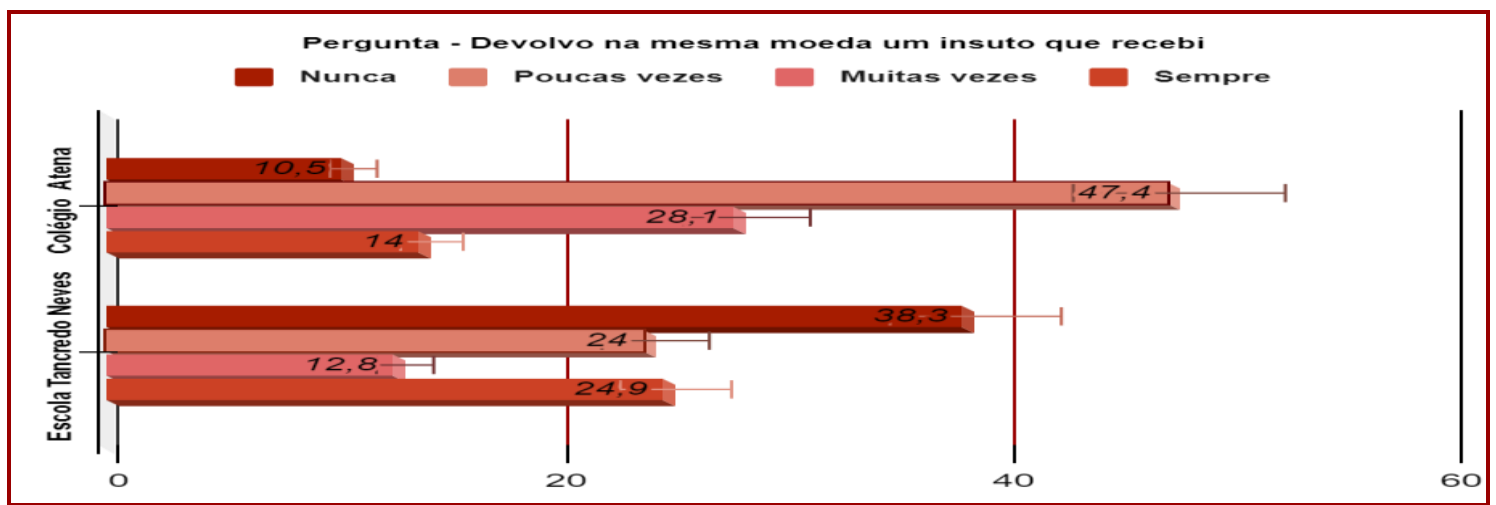

$\mathrm{Na}$ questão de revidar observa-se que dos inquiridos do Colégio Atena (6) alunos assumirem nunca revidar aos insultos, (16) muitas vezes, (27) poucas vezes e (8) sempre; já na Escola Tancredo Neves (I8) nunca revidam, (I6) poucas vezes, (6) muitas vezes e (7) sempre. Observa-se, no Colégio Atena, uma ligeira inclinação negativa em detrimento da Escola Tancredo Neves.

Nesse sentido, Cury (2019, p. 4I) alerta que 'Quem gravita em torno dos problemas e não aprende a fazer uma parada introspectiva para pensar antes de reagir faz das pequenas barreiras obstáculos intransponíveis, das pequenas dificuldades, problemas insolúveis, das pequenas decepções, um mar de sofrimento. 
Tabela 9: Resultado da dimensão autocontrole no que se refere a frear impulsos.

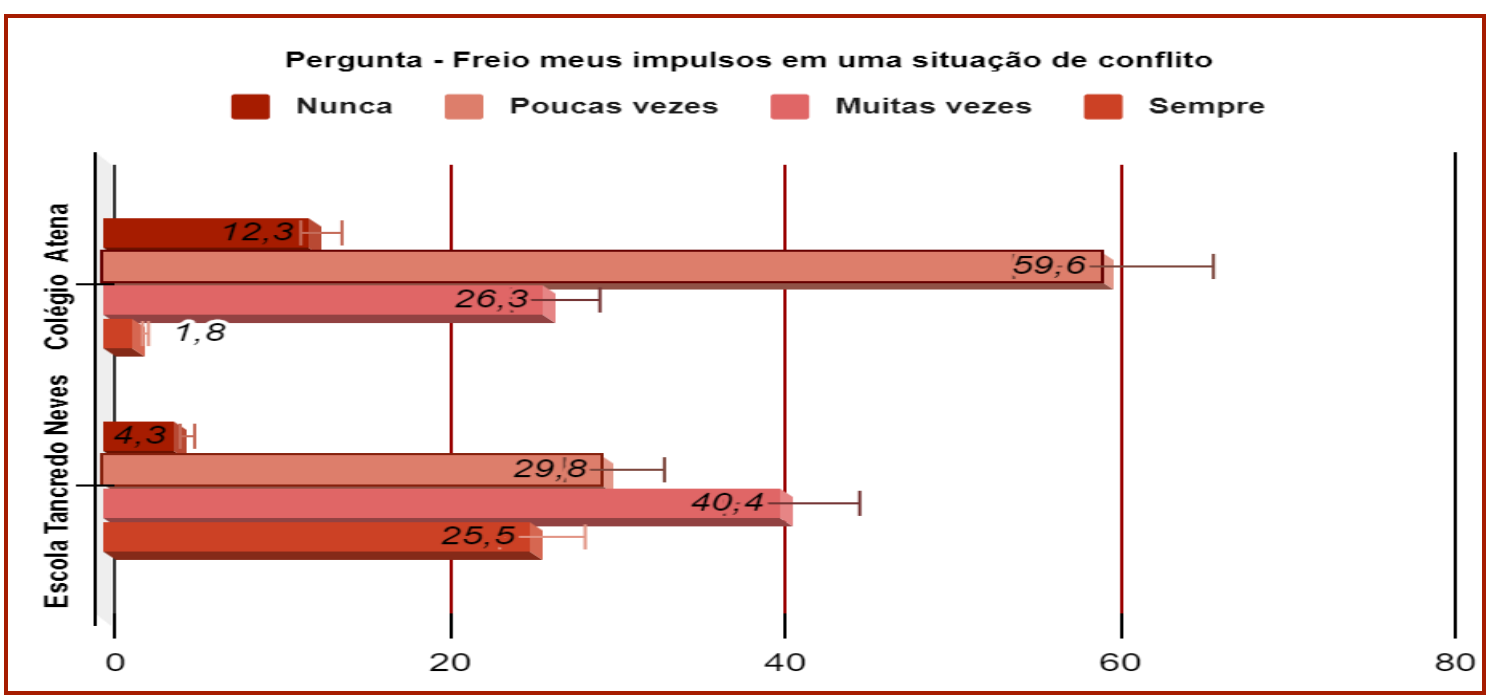

$\mathrm{Na}$ análise de situações conflituosas, observa-se que dos inquiridos do Colégio Atena

(7) assinalaram sempre, (15) muitas vezes, (34) poucas vezes e apenas um sempre. Olhando para a Escola Tancredo Neves (I2) respondeu sempre, (19) muitas vezes, (I4) poucas vezes e (2) nunca.

Percebe-se que o domínio dos participantes da pesquisa, aqui, é pouco elevado, contudo, os indivíduos da Escola Tancredo Neves apresentam melhor capacidade de frear os impulsos comparados aos do Colégio Atena. Diante desse cenário, corrobora-se com o que diz Sousa (2021) ao mencionar a necessidade de o indivíduo ter controle e domínio emocional para que flua ações coerentes que favoreçam as relações. É necessário equilíbrio ao lidar com a adversidade.

Tabela ro: Resultado da dimensão autocontrole no que se refere a reagir a agressão.

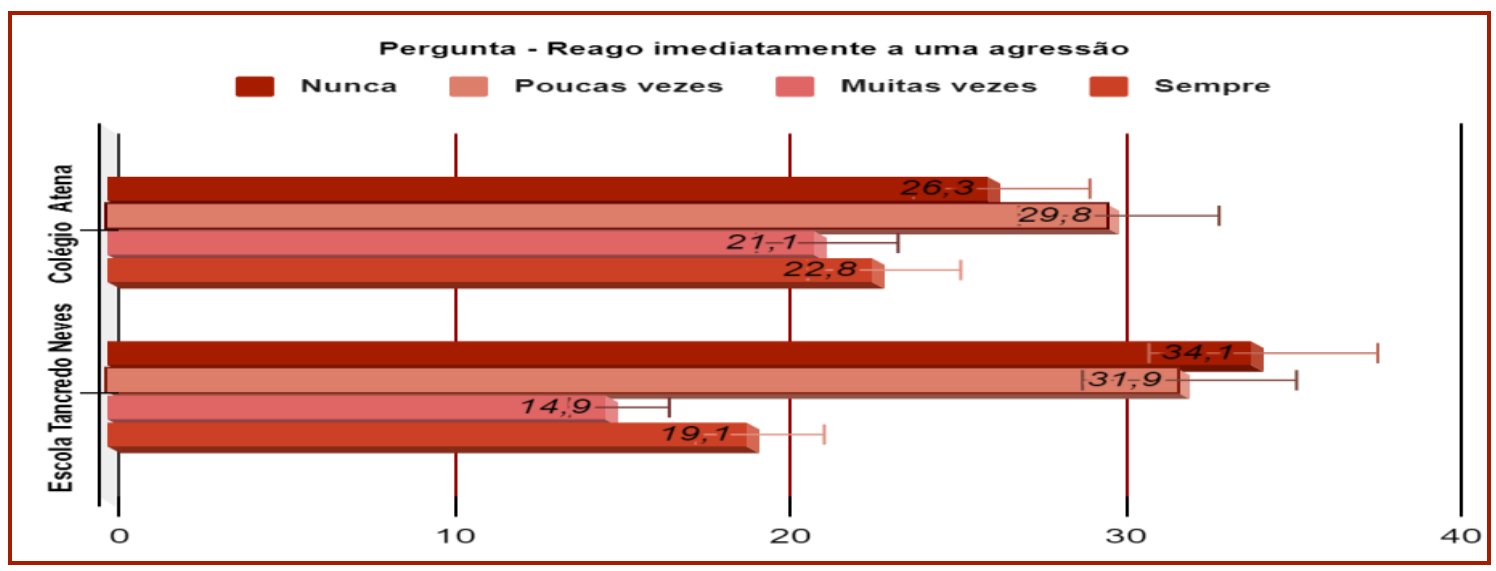


$\mathrm{Na}$ análise do controle das reações quando tratados com agressividade, dos questionados no Colégio Atena, (I5) afirmam nunca reagir, (17) afirmam poucas vezes, (I2) confirmam muitas vezes e (13) sempre. Na Escola Tancredo Neves se contempla (16) nunca, (I5) poucas vezes, (7) muitas vezes e 9 sempre demonstram comportamento desafrontador. Observa-se, portanto, melhor resultado na Escola Tancredo Neves.

A excelência emocional domina a reação à agressão. $O$ fato de ser agredido tende a desencadear sofrimento e reciprocidade à violência, assim, Berra (2018, p.II) menciona que “a formação de caráter é constituída quando se levar adiante a constância da prática de bons hábitos que necessitam estar em harmonia com o raciocínio".

Tabela Ir: Resultado do autocontrole no que se refere a resposta rápida.

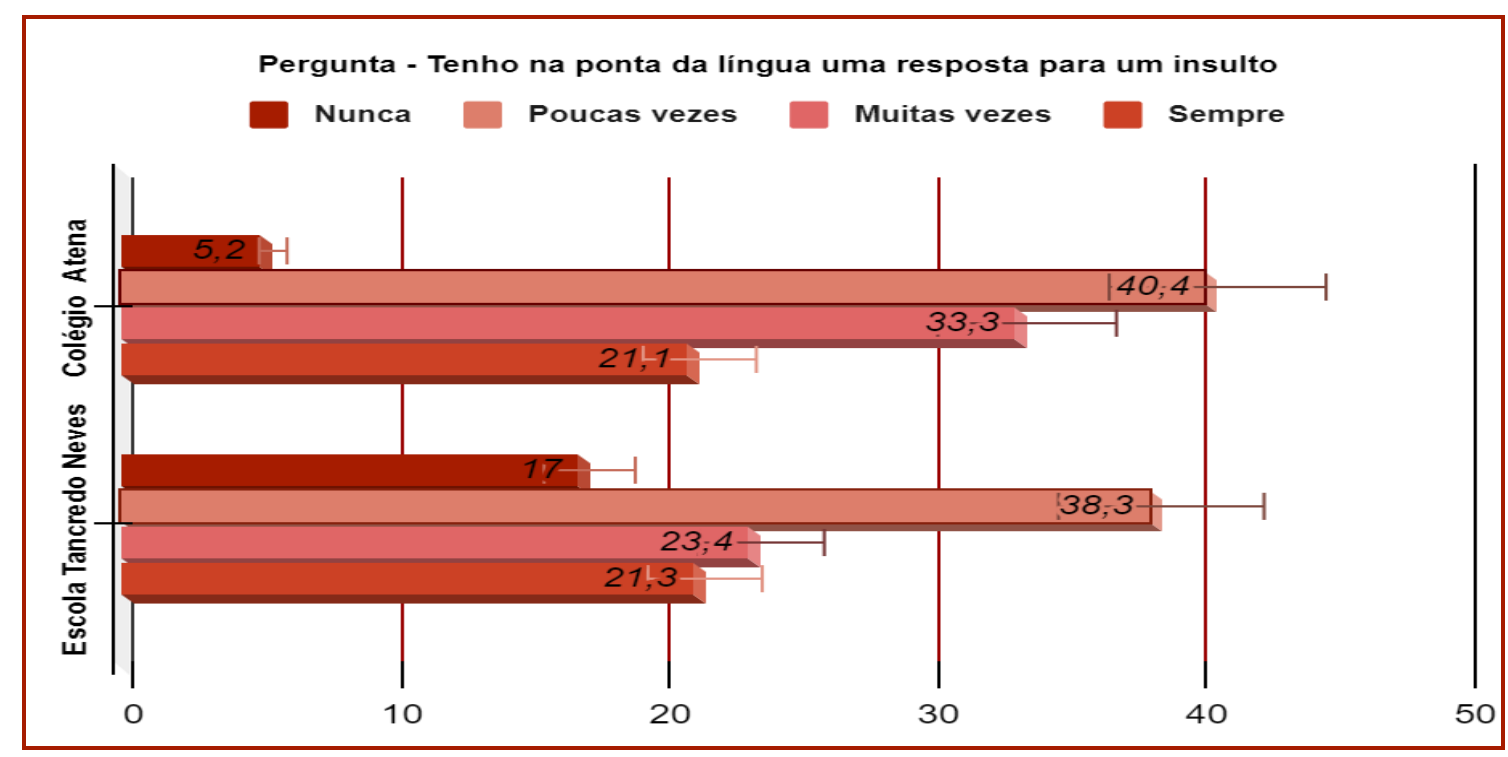

Neste item que analisa a afronta verbal, tem-se como resultado no Colégio Atena, dos estudantes questionados (3) nunca respondem aos insultos, (23) poucas vezes, (19) muitas vezes e (I2) sempre. Na Escola Tancredo Neves (8) nunca responde, (I8) poucas vezes, (II) muitas vezes e (IO) sempre.

$\mathrm{O}$ fato de reagir a insultos de forma agressiva denota imaturidade emocional. $\mathrm{O}$ gerenciamento e a regulação das emoções é o meio seguro para o controle da reação impulsiva. Cury (2015, p. II5) tece um comentário nesse sentido, e, segundo ele, para interagir com humanos o silêncio e a tolerância são essenciais. 
Tabela 12: Resultado do autocontrole no que se refere a impulsos.

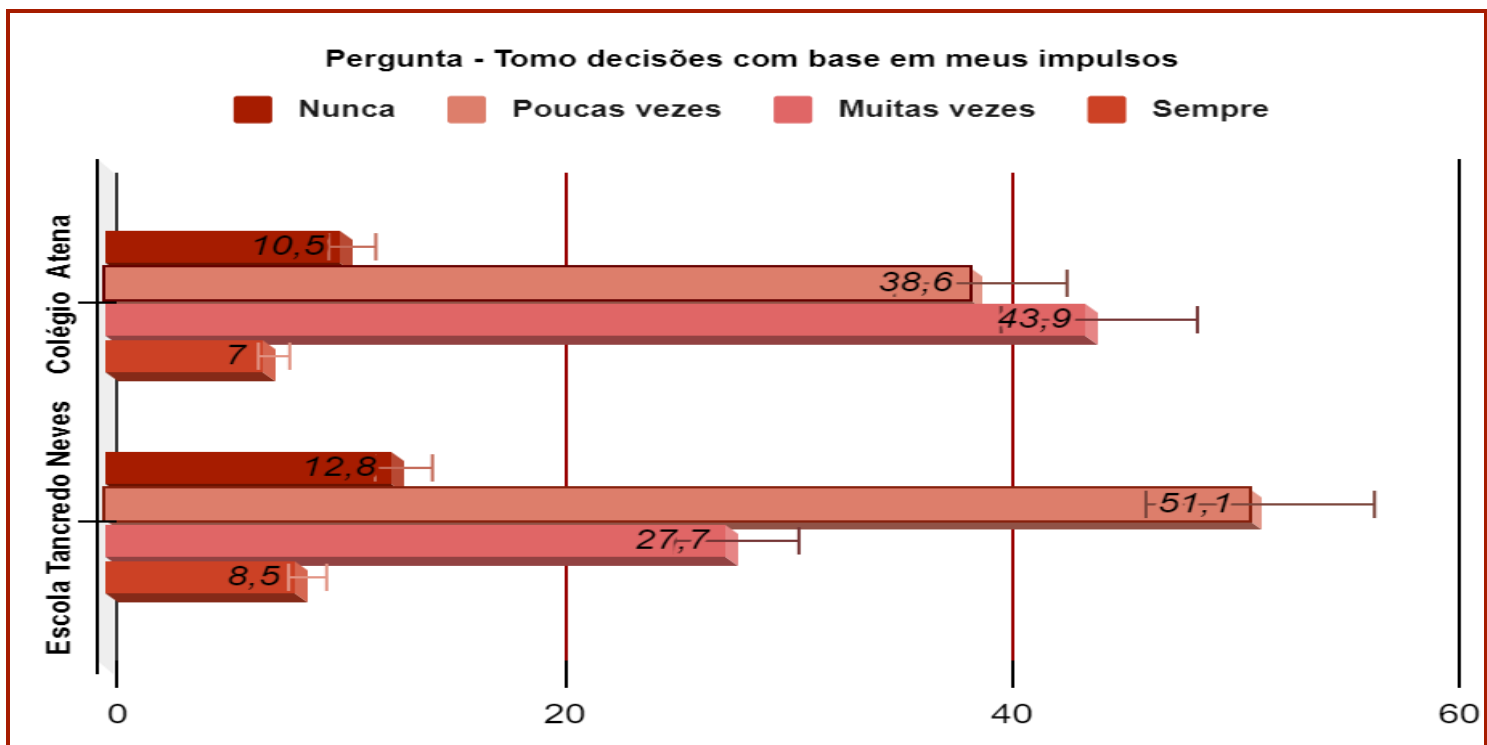

Este tópico investiga-se o comportamento impulsivo e, enxerga-se nos pesquisados do Colégio Atena (6) inquiridos nunca tomando decisões impulsivas, (22) poucas vezes, (25) muitas vezes e (4) sempre. Por outro lado, na Escola Tancredo Neves, dos 47 questionados (6) nunca tomam decisões por impulso, (24) poucas vezes, (13) muitas vezes e (4) sempre.

Evidencia-se a continuidade de melhor desenvolvimento emocional nos discentes da Escola Tancredo Neves.

A tomada de decisões com base em impulsos aponta para um chamamento à regulação da emoção, Vigotski (2004, p. 77) elenca que o processo emocional envolve "motivação, tendência à ação, o impulso, estreitamente imbricados nos processos e que fazem de nossas emoções motivações muito fortes e que influenciam nosso comportamento".

Nesse viés, no que se refere ao autocontrole, e que envolve diversas esferas na investigação ponderadas, de Oliveira, de Figueiredo, \& Dutra (2020) caucionam que o autocontrole é desenvolvível e o indivíduo provido desse domínio emocional é capaz de contornar situações adversas fazendo o jogo inverso ao sentimento ruim, ou seja, transformando situações desagradáveis em crescimento e construindo um comportamento equilibrado que vai conduzir o modo pelo qual o indivíduo vai interagir em sua trajetória de vida. 


\section{CONSIDERAÇÕES FINAIS}

A inteligência emocional abarca um conjunto de características pessoais no âmbito das emoções e envolve a motivação em suas diversas facetas, a regulação e controle do comportamento, a consciência de si mesmo em observância aos próprios sentimentos, a capacidade de enxergar os outros a partir do seu próprio espelho e a interação social, incorporando assim as relações intrapessoal e interpessoal.

A investigação, ora em argumentação, ocupou-se de analisar o efeito da aprendizagem emocional em alunos alfabetizados sob a perspectiva da inteligência emocional dos $8^{\circ}$ e $9^{\circ}$ ano do Colégio Atena (escola particular) e da Escola Tancredo Neves (escola pública), especificamente, em avaliar o a habilidade do autocontrole, e, por fim, correlacionar as possíveis diferenças, através da análise de dados, entre os discentes da escola Tancredo Neves, não alfabetizados emocionalmente aos da escola privada, Colégio Atena, que estão inseridos em programas de desenvolvimento emocional, quanto aos domínios dessas aptidões emocionais.

Através da análise dos dados, verificou-se a proximidade quanto ao fator gênero, prevalecendo ligeiramente o feminino; quanto à distribuição por idades a percentagem é maior entre (I3 e I4 anos), já a escolaridade, em ambas instituições, se deu a estudantes do oitavo e nono ano do Ensino Fundamental.

$\mathrm{Na}$ análise da componente emocional do autocontrole, que revela a capacidade do indivíduo em controlar as suas emoções e concernentes manifestações, envolvendo o gerenciamento e a regulação emocional, bem como dominar os próprios sentimentos, reconhecê-los, analisar e refletir sobre eles, no cenário geral se pode observar que as duas instituições menos de 50\% assumem domínio do autocontrole, contudo, os participantes da Escola Tancredo Neves apresentaram ligeira vantagem nessa componente emocional comparado aos inquiridos do Colégio Atena, espelhando melhor equilíbrio emocional. Nas questões tais como a prontidão a responder um desaforo, revidar, reagir a agressão, responder a insultos, bem como tomar decisões impulsivas, as duas instituições têm um público maior que 50\% exerce negativamente esse comportamento, entretanto, observa-se 
que se trata de itens de conotação negativa, ou seja, não se tem como favorável, também, esse resultado.

Ainda discorrendo sobre a habilidade do autocontrole, destaca-se uma disparidade maior entre as escolas na observação do controle de impulsos em situações de conflito, em reagir com cautela diante de provocações e no controle de sentimentos perturbadores; menos de $30 \%$ dos inquiridos no Colégio Atena apontaram positivamente para essa aptidão. Já na Escola Tancredo Neves mais de 50\% abarcam essa conduta, retratando, de novo, melhor equilíbrio emocional. Outro ponto que chamou à atenção foram os resultados do falar sem pensar, ambas as escolas têm representatividade de menos da metade com esse domínio.

Portanto, na condensação de todos os itens que avaliaram o autocontrole, depara-se com um cenário indesejado. Evidencia-se também que a população da Escola Tancredo Neves espelha, embora sutilmente, melhor desenvolvimento emocional.

As emoções tendem a se manifestarem na forma de padrões de pensamentos, sentimentos, comportamentos e influências, contudo, são moldáveis, ou seja, podem ser aprendidas em contextos formais e informais de aprendizagem, ademais, podem exercer influência sobre diversos resultados na vida das pessoas, em diferentes e todas as fases do desenvolvimento, contribuindo positivo ou negativamente para o crescimento pessoal.

Com as mudanças bruscas da sociedade pós-contemporânea não se pode ignorar a interferência provocada no comportamento dos humanos, o que exige uma maior conscientização e envolvência por parte dos gestores da educação no sentido de aplicabilidade no currículo escolar relativos às componentes emocionais.

Aponta-se como limitações, nesse estudo, a dificuldade em obter uma amostra mais significativa devido a ausência de escolas que disponham de programas de desenvolvimento da inteligência emocional dentro do contexto da habilidade questionada.

Apesar das dificuldades de exercer o autocontrole espelhada pelos discentes nesta investigação, os resultados indicaram que muitos destes aprenderam e desenvolveram competências emocionais em suas vivências. Sabe-se que a pesquisa não fez referência a consciência da necessidade de mudar as suas práticas e se autoajudar ou buscar ajuda no desenvolvimento da inteligência emocional. Nesse sentido, torna-se pertinente a 
continuidade do estudo no intuito de investigar se com o passar do tempo houve mudança de consciência na conduta emocional.

\section{REFERÊNCIAS BIBLIOGRÁFICAS}

AMESTOY, Simone Coelho. Inteligência emocional: habilidade relacional para o enfermeiro-líder na linha de frente contra o novo Coronavírus/Emotional intelligence: relationship skill for the nurse-leader on the front line against the new Coronavirus. Journal of Nursing and Health, v. Io, n. 4, 2020.

COSTA, Maria Gorete Xavier da. A educação emocional e o curso de Pedagogia da Universidade Federal da Paraíba. 2017.

CURY, AUGUSTO JORGE. Ansiedade: como enfrentar o mal do século. Saraiva Educação SA, 2017.

DA FONSECA, João José Saraiva. Apostila de metodologia da pesquisa científica. João José Saraiva da Fonseca, 2002.

DE MORAIS, Fabiano José et al. Gestão das emoções em centrais de atendimento telefônico. Revista Pensamento Contemporâneo em Administração, v. 9, n. 3, p. 15-29, 2015.

DE OLIVEIRA, Giovana Aparecida; DE FIGUEIREDO, Taynara Barbosa; DUTRA, Júlio Afonso Alves. Inteligência Emocional e o Capital Psicológico nas Organizações e em suas Lideranças/Emotional Intelligence and Psychological Capital in Organizations and their Leadership. ID on line REVISTA DE PSICOLOGIA, v. I4, n. 52, p. 185-201, 2020.

DOS SANTOS, Fernanda Marsaro. Análise de conteúdo: a visão de Laurence Bardin. 2012.

SOUSA, Yann Rodrigues. Inteligência emocional nas organizações. 202I 
GIL, Antonio Carlos. Métodos e técnicas de pesquisa social. 6. ed. Ediitora Atlas SA, 2008.

GODIEL RAMOS, Teodora Yolanda. Inteligencia emocional en los niños y niñas de 5 años de la IEI $N^{\circ} 270$ Independencia Puno-2016. 2018.

GOLEMAN, Daniel. O cérebro e a inteligência emocional: novas perspectivas. Objetiva, 2012.

GROSS, James J. Emotion regulation. Handbook of emotions, v. 3, n. 3, p. 497-513, 2008. HANSEN, Rogério et al. Inteligência Emocional e Engajamento no Ambiente de Trabalho: Estudo Empírico a Partir de Gestores e Equipes. Revista Gestão Organizacional, v. II, n. I, 2018.

LE BRETON, David. Antropologia das emoções. Petrópolis, RJ: Vozes, 2019.

LEITE, Rosa Domingues; CABANAS, Ana. A PEDAGOGIDA DO OLHAR: FEELING NO PROCESSO EDUCACIONAL. Revista Científica Educ@ ção, v. 2, n. 3, p. 423-439, 2018.

MACHADO, Dimitrius Gonçalves. A categorização do indisciplinado na escola atual: uma análise a partir do transbordamento da literatura de autoajuda na educação. 2020.

MAYER, John D. et al. Models of emotional intelligence. JD Mayer, 2000.

MODOLON, Elizângela Corrêa; VITOR, Janaína Neves. GESTÃO DA EMOÇÃO E CONFLITOS: UM ESTUDO DE CASO NO INSTITUTO FEDERAL DE SANTA CATARINA (IFSC) CAMPUS TUBARÃO. 2020. 
RICARTE, Mirela Dantas. Construção de um instrumento para avaliação da regulação emocional em crianças e adolescentes. 2016. Dissertação de Mestrado. Universidade Federal de Pernambuco.

RICHARDSON, Roberto Jarry. Pesquisa Social: Métodos e técnicas, $3^{\text {a }}$ Edição Editora Atlas SA São Paulo. 1999.

SALES, Maria Veronica Santana et al. A INFLUÊNCIA DAS EMOÇÕẼ NO DESENVOLVIMENTO ESCOLAR DOS PRÉ-ADOLESCENTES ENAMORADOS. Scientia Generalis, v. 2, n. 2, p. 47-59, 2021.

SIQUEIRA, Mirlene Maria Matias; BARBOSA, Nilton César; ALVES, Matianny Thyssen. Construção e validação fatorial de uma medida de inteligência emocional. Psicologia: Teoria e Pesquisa, v. 15, n. 2, p. 143-152, 1999.

SIQUEIRA, Sarah David. A neurobiologia das emoções e sua integração com a cognição em crianças no ambiente escolar. 2018.

SIQUEIRA, Jéssica S.; SANTILLO, Priscila A. de S. O impacto da Inteligência Emocional na Formação de Líderes Organizacionais. 2019.

SOUZA, Joelson Carvalho et al. A influência das emoções no aprendizado de escolares. Revista Brasileira de Estudos Pedagógicos, v. IoI, p. 382-403, 2020.

SOUSA, Yann Rodrigues. Inteligência emocional nas organizações. 2021.

VIGOTSKI, Lev Semenovich. Sobre os sistemas psicológicos. VIGOTSKI, LS Teoria e método em psicologia. São Paulo: Martins Fontes, 2004. 
XAVIER, Vinícius Pereira Pinto. EMOÇÃO, REgUlAÇÃO EMOCIONAL E COMPORTAMENTO. Singular. Sociais e Humanidades, v. I, n. I, p. 31-39, 2019. 